(RESEARCH ARTICLE)

\title{
Curcumin analogues for possible cancer treatment A QSAR and partial ordering study
}

\author{
Lars Carlsen 1, ${ }^{*}$, Poul Erik Hansen ${ }^{2}$, Bahjat A Saeed ${ }^{3}$ and Rita S Elias 4 \\ ${ }^{1}$ Awareness Center, Linkøpingvej 35, Trekroner, DK-4000 Roskilde, Denmark. \\ 2 Department of Science and Environment, Roskilde University, Denmark. \\ ${ }^{3}$ Department of Chemistry, College of Education for Pure Sciences, University of Basrah, Iraq. \\ ${ }^{4}$ Department of Pharmaceutical Chemistry, College of Pharmacy, University of Basrah, Iraq.
}

World Journal of Biological and Pharmaceutical Research, 2021, 01(02), 001-016

Publication history: Received on 19 June 2021; revised on 31 July 2021; accepted on 01 August 2021

Article DOI: https://doi.org/10.53346/wjbpr.2021.1.2.0126

\begin{abstract}
The possible effect of curcumin as a potential natural cancer treatment drug has been intensively discussed. In the present study the probabilities of a series of curcumin analogues to possess potential as antineoplastic, prostate cancer treatment and anticarcinogenic agents has been studied theoretically applying a selection of quantitative structureactivity relation and absorption, distribution, metabolism, and excretion (ADME) approaches. From spectroscopic studies it is evident that these compounds can be found in both enol and diketo forms, the former in general the more predominant in non-polar solvents, whereas in polar solvents, like water an increasing amount of the diketo form can be noted. Hence, the probabilities for both the enols and diketo forms to possess the above-mentioned effects were studied. In most cases the enol form shows the highest probabilities for being effective although the differences are not significant. Thus, it is suggested to look at the sum of effects of the keto and the enol forms in relation to the possible therapeutic effects of the compounds here studied.
\end{abstract}

Keywords: Curcumin; Curcuminoids; Antineoplastic effects; Prostate cancer treatment; Anticarcinogenic effects

\section{Introduction}

Curcumin ((1E,6E)-1,7-Bis(4-hydroxy-3-methoxyphenyl) hepta-1,6-diene-3,5-dione; CAS 458-37-7) (Fig. 1) is a natural product extracted from Turmeric (Curcuma longa) of the ginger family. Curcumin has over the years been reported to have a variety of positive health effects among others anti-inflammatory and anti-carcinogenic effects [1], especially the possibly effect on prostate cancer has received attention [2]. The presence of extra methoxy groups have been shown to have beneficial effects $[1,3]$. In addition to curcumine, small amounts of demethoxy- and didemethyoxycurcumine are also found. It is interesting to test their potential as drugs.

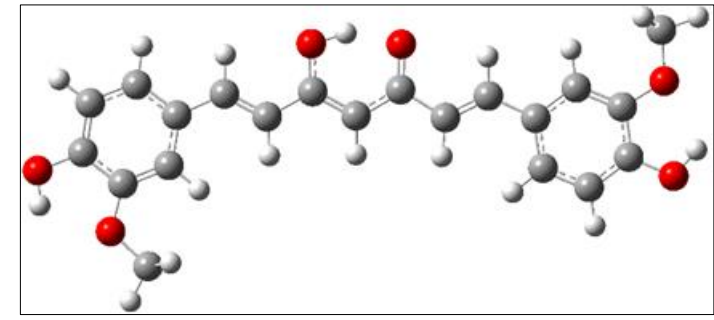

Enol form

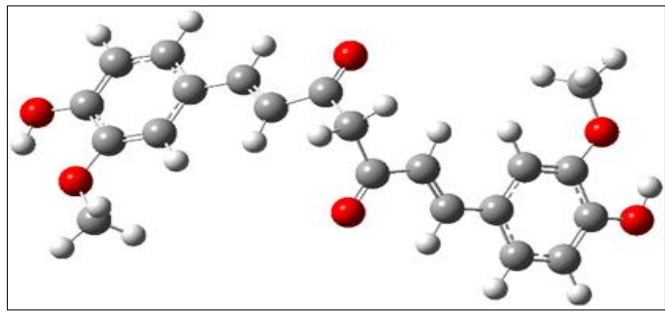

Diketo form

Figure 1 a) Enol and b) diketo forms of curcumin

\footnotetext{
${ }^{*}$ Corresponding author: Lars Carlsen; Email: LC@AwarenessCenter.dk Awareness Center, Linkøpingvej 35, DK-4000 Roskilde, Denmark. 
The actual use of curcumin as a drug has been rather limited [4] due to a rather low solubility (3.12 $\mathrm{mg} / \mathrm{L}$ [5], and bioavailability [6]. Studies by several groups showed that curcumin doses administrated orally gave exceptionally low levels of $0.006(0.005 \mu \mathrm{g} / \mathrm{mL}$ [7], $0.4-3.6 \mu \mathrm{M}$ [8], $51.2 \mathrm{ng} / \mathrm{mL}$ [9] in serum, $11.1 \pm 0.6 \mathrm{nmol} / \mathrm{mL}$ [10] in plasma and 7-20 $\mathrm{nmol} / \mathrm{g}[11]$ (in colorectum).<smiles></smiles>

Figure 2 General substitution pattern for the curcumin analogues (enol form)

Table 1 Substitution patterns for the curcumin analogues

\begin{tabular}{|c|c|c|c|c|c|c|c|}
\hline ID & R1 & R2 & R3 & ID & R1 & R2 & R3 \\
\hline H1 & $\mathrm{H}$ & $\mathrm{H}$ & $\mathrm{H}$ & OMe1 & $\mathrm{H}$ & $\mathrm{H}$ & $\mathrm{OMe}$ \\
\hline $\mathrm{H} 2$ & $\mathrm{Br}$ & $\mathrm{H}$ & $\mathrm{H}$ & $\mathrm{OMe} 2$ & $\mathrm{Br}$ & $\mathrm{H}$ & $\mathrm{OMe}$ \\
\hline H3 & $\mathrm{F}$ & $\mathrm{H}$ & $\mathrm{H}$ & OMe3 & $\mathrm{F}$ & $\mathrm{H}$ & $\mathrm{OMe}$ \\
\hline $\mathrm{H} 4$ & $\mathrm{Cl}$ & $\mathrm{H}$ & $\mathrm{H}$ & $\mathrm{OMe} 4$ & $\mathrm{Cl}$ & $\mathrm{H}$ & $\mathrm{OMe}$ \\
\hline H5 & $\mathrm{OMe}$ & $\mathrm{H}$ & $\mathrm{H}$ & OMe5 & $\mathrm{OMe}$ & $\mathrm{H}$ & $\mathrm{OMe}$ \\
\hline H6 & $\mathrm{N}(\mathrm{Me}) 2$ & $\mathrm{H}$ & $\mathrm{H}$ & 0Me6 & $\mathrm{N}(\mathrm{Me}) 2$ & $\mathrm{H}$ & $\mathrm{OMe}$ \\
\hline H7 & $\mathrm{H}$ & $\mathrm{Cl}$ & $\mathrm{H}$ & OMe7 & $\mathrm{H}$ & $\mathrm{Cl}$ & $\mathrm{OMe}$ \\
\hline H8 & $\mathrm{Br}$ & $\mathrm{Cl}$ & $\mathrm{H}$ & OMe8 & $\mathrm{Br}$ & $\mathrm{Cl}$ & $\mathrm{OMe}$ \\
\hline H9 & $\mathrm{F}$ & $\mathrm{Cl}$ & $\mathrm{H}$ & OMe9 & $\mathrm{F}$ & $\mathrm{Cl}$ & $\mathrm{OMe}$ \\
\hline H10 & $\mathrm{Cl}$ & $\mathrm{Cl}$ & $\mathrm{H}$ & OMe10 & $\mathrm{Cl}$ & $\mathrm{Cl}$ & $\mathrm{OMe}$ \\
\hline H11 & $\mathrm{OMe}$ & $\mathrm{Cl}$ & $\mathrm{H}$ & OMe11 & $\mathrm{OMe}$ & $\mathrm{Cl}$ & $\mathrm{OMe}$ \\
\hline H12 & $\mathrm{N}(\mathrm{Me}) 2$ & $\mathrm{Cl}$ & $\mathrm{H}$ & OMe12 & $\mathrm{N}(\mathrm{Me}) 2$ & $\mathrm{Cl}$ & $\mathrm{OMe}$ \\
\hline H13 & $\mathrm{H}$ & $\mathrm{Me}$ & $\mathrm{H}$ & OMe13 & $\mathrm{H}$ & $\mathrm{Me}$ & $\mathrm{OMe}$ \\
\hline H14 & $\mathrm{Br}$ & $\mathrm{Me}$ & $\mathrm{H}$ & OMe14 & $\mathrm{Br}$ & $\mathrm{Me}$ & $\mathrm{OMe}$ \\
\hline H15 & $\mathrm{F}$ & $\mathrm{Me}$ & $\mathrm{H}$ & OMe15 & $\mathrm{F}$ & $\mathrm{Me}$ & $\mathrm{OMe}$ \\
\hline H16 & $\mathrm{Cl}$ & $\mathrm{Me}$ & $\mathrm{H}$ & OMe16 & $\mathrm{Cl}$ & $\mathrm{Me}$ & $\mathrm{OMe}$ \\
\hline H17 & $\mathrm{OMe}$ & $\mathrm{Me}$ & $\mathrm{H}$ & OMe17 & $\mathrm{OMe}$ & $\mathrm{Me}$ & $\mathrm{OMe}$ \\
\hline H18 & $\mathrm{N}(\mathrm{Me}) 2$ & $\mathrm{Me}$ & $\mathrm{H}$ & OMe18 & $\mathrm{N}(\mathrm{Me}) 2$ & $\mathrm{Me}$ & $\mathrm{OMe}$ \\
\hline $\mathrm{OH} 1$ & $\mathrm{OH}$ & $\mathrm{H}$ & $\mathrm{H}$ & $\mathrm{OH} 2$ & $\mathrm{OH}$ & $\mathrm{H}$ & $\mathrm{OMe}$ \\
\hline
\end{tabular}

In the present theoretic study curcumin and a series of curcumin analogues have been investigated with the aim to test compounds that can easily be synthesized, but also to test how simple substituents can change the structure. Focus is on the possible positive effect on prostate cancer treatment as well as general anti-carcinogenic and anti-neoplastic 
effects. The theoretical study enables the screening of a large number of compounds. Thus, the probabilities that the studies compounds possess or don't possess a given effect have been calculated for both the enol and diketo forms. The possible effects of the two forms have been compared as function of the substitution pattern. Subsequently, partial ordering was applied to verify the most beneficial substitution pattern assuming a wish for an optimal combined effect of, e.g., anti-neoplastic, anti-carcinogenic and prostate cancer treatment. Eventually the ADME characteristics are discussed for compounds with selected substitution patterns. In Table 1 and Fig. 2 the structures of the investigated compounds are summarized. In all cases, both the enol and the diketo forms were studied, the general formula being depicted in Fig. 2. In the following, the enol and diketo form will be denoted with an e and k prescripts respectively, as e.g., eH1 and kH1.

In addition, three isocurcumines (Fig. 3) have also been investigated.

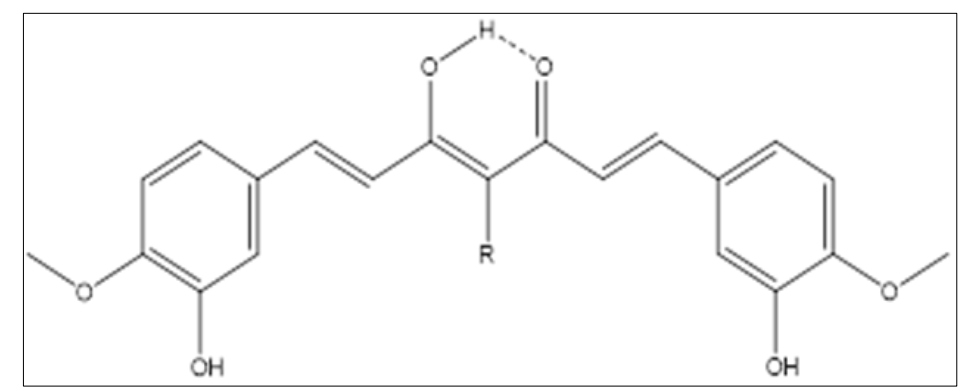

Figure 3 Isocurcumines. $\mathrm{iC} 1: \mathrm{R}=\mathrm{H}, \mathrm{iC} 2: \mathrm{R}=\mathrm{Cl}$ and $\mathrm{iC} 3: \mathrm{R}=\mathrm{Me}$

As the amounts of enol and keto-forms matter, NMR and UV experiments have been performed to investigate this for the new isocurcumins and experiments have been done to get an impression of the importance of the solvent.

\section{Methods}

\subsection{Quantitative Structure-Activity Relationships (QSAR)}

Structural QSAR calculations including energy considerations were calculated applying the semi-empirical AM1 method as implemented in the OASIS software [12]. The probabilities for the compounds to possess (Pa) or not to possess (Pi) a given effect were calculated using the PASS Online software (newest online version) [13] and the Physico-chemical characteristics as well as Pharmacokinetic calculations were estimated applying the PK-explorer of the Percepta software from ACD/Labs [14]. An evaluation of the druglikeness of the different structures, based the Lipinski, Ghose, Veber, Egan and Muegge methods was carried out by the Swiss ADME software [15]. In all cases detailed description of the models are outside the scope of the present study and are available in the given references and will thus not be repeated here. In all cases, SMILES notations for the single compounds were used as input in the calculations.

\subsection{Density Functional Calculations (DFT)}

Density functional theory calculations (DFT) with the standard B3LYP $[16,17]$ approach have been carried out by using the Gaussian16 software [18]. The studied molecules were freely optimized either in the gas phase or in the solvent using the 6-311++G $(2 \mathrm{~d}, \mathrm{p})$ basis set. It has been shown that the B3LYP functional is suitable for studying both inter-and intramolecular hydrogen bonds if it is conducted with a basis set including diffuse functions $[19,20]$.

For simulation in solution, e.g., water, chloroform or DMSO the Integral Equation Formalism Polarizable Continuum Model (IEFPCM) [21] was used.

\subsection{Partial ordering}

In its basis partial ordering appears pretty simple as the only mathematical relation among the objects is " $\leq$ " [22,23]. The basis for a comparison of objects, here curcumin analogues, characterized by the subset of indicators describing their probabilities for being an active prostate cancer drug as well as the probabilities for exhibiting anti-neoplastic and anti-carcinogenic activity. These indicators, rj, characterizes the single compounds. Thus, characterizing one compound (x) by a set of indicators $\mathrm{rj}(\mathrm{x}), \mathrm{j}=1, \ldots, \mathrm{m}$, where $\mathrm{m}$ is the number of indicators, can be compared to another compound (y), characterized by the indicators $\operatorname{rj}(\mathrm{y})$, when 
$r_{j}(y) \leq r_{j}(x)$ for all $j=1, \ldots, m$

Eq. 1 is a very hard and strict requirement for establishing a comparison. It demands that all indicators of $\mathrm{x}$ should be better (or at least equal) than those of $\mathrm{y}$. Further, let $\mathrm{X}$ be the subset of compounds included in the analyses, $\mathrm{x}$ will be ordered higher (better) than $\mathrm{y}$, i.e., $\mathrm{x}>\mathrm{y}$, if at least one of the indicator values for $\mathrm{x}$ is higher than the corresponding indicator value for $y$ and no indicator for $\mathrm{x}$ is lower than the corresponding indicator value for $\mathrm{y}$. On the other hand, if $\operatorname{rj}(\mathrm{x})>\operatorname{rj}(\mathrm{y})$ for some indicator $\mathrm{j}$ and $\mathrm{ri}(\mathrm{x})<\operatorname{ri}(\mathrm{y})$ for some other indicator $\mathrm{i}$, $\mathrm{x}$ and $\mathrm{y}$ will be called incomparable (notation: $\mathrm{x} \| \mathrm{y}$ ) expressing the mathematical contradiction due to conflicting indicator values. A set of mutual incomparable objects is called an antichain. When all indicator values for $\mathrm{x}$ are equal to the corresponding indicator values for $\mathrm{y}$, i.e., $\operatorname{rj}(\mathrm{x})=\operatorname{rj}(\mathrm{y})$ for all $\mathrm{j}$, the two objects/nations will have identical rank and will be considered as equivalent, i.e., $\mathrm{x} \sim \mathrm{y}$. The analysis of eq. 1 results in a graph, the Hasse diagram. Hasse diagrams are unique visualizations of the order relations due to eq. 1.

\subsubsection{The Hasse diagram}

The eq. 1 is the basic for the Hasse diagram technique (HDT) [22, 23]. Hasse diagrams are visual representation of the partial order. In the Hasse diagram comparable objects are connected by a sequence of lines [24-26].

\subsubsection{The more elaborate analyses}

In addition to the basic partial ordering tools some more elaborate analyses have been used including average ranks [27-29] and sensitivity analysis [23,30], the latter gives an insight in the relative importance of the included indicators $[23,30]$. For detailed information on the single tool, the cited literature should be consulted as a detailed description is outside the scope of the present paper.

\subsubsection{Software}

All partial order analyses were carried out using the PyHasse software [30]. PyHasse is programmed using the interpreter language Python (version 2.6). Today, the software package contains more than one hundred specialized modules and is available upon request from the developer, Dr. R. Bruggemann.

\section{Results and discussion}

\subsection{Structure}

Curcumin and its derivatives may exist as both an enol and a diketo-form (see Fig. 1). The structure of the enol-form has a strong intramolecular hydrogen bond, whereas the diketo-form, although traditionally drawn like Fig. 1b, is more on a trans-like form as seen in Fig. 4

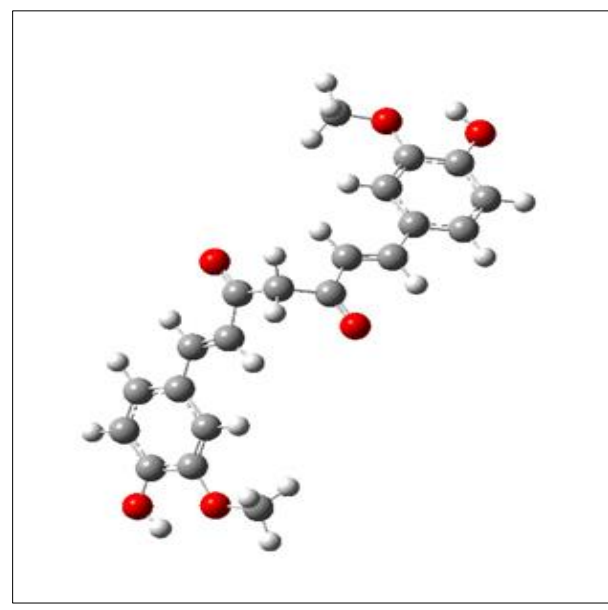

Figure 4 Calculated structure of the diketo-form of curcumin

\subsection{Diketo-enol ratio}

The ratio between the enol and the diketo-form depends on the substituent at C-4 and on the polarity of the solvent. Large alkyl substituents and polar solvents increase the amount of diketo-form [31]. The amount of the diketo-form for 
curcumin in water/ethanol mixture showed a predominance of the keto form in $90 \%$ water [32]. A similar experiment done on eOMe5 also showed an increase in the amount of the keto-form, when increasing the percentage of water (see Fig. S3). An NMR experiment using D20/DMSO-d6 as solvent showed no keto-form [33]. This was also studied in DMSOwater buffers from pH 3 to 9 again finding no keto-form [33]. A repetition of this experiment showed at 55\% water the amount of keto-form to be 18+-5\% (see Suppl. Mat. Fig. S2).

In case of the isocurcumins the ratios in DMSO-d6 were determined from $1 \mathrm{H}$ NMR spectra. For the isocurcumin itself no keto-form could be detected, for the 4-chloro-derivative the keto percentage is measured as $20 \%$, whereas for the 4 methylderivative, the percentage is as high as 55\% (Figs. S4-S10).

Theoretical DFT calculations, B3LYP/6-311++G(2d, p) in the Polarizable Continuum Model, confirm the solvent effect, but the calculations give much lower amounts of the diketo-form (Table 2) in agreement with the NMR experiments.

Table 2 Calculated total energies (Hartree) of substituted curcumins in different solvents, B3LYP/6-311++G(2d,p)

\begin{tabular}{|l|c|c|c|c|}
\hline \multicolumn{1}{|c|}{ Molecule, Total energy, } & Gas phase & Water & DMSO & $\mathbf{C H C l}_{\mathbf{3}}$ \\
\hline Curcumin-enol & -1263.977485 & -1263.996225 & -1263.995866 & -1263.990449 \\
\hline Curcumin-diketo-trans & -1263.967328 & -1263.987823 & -1263.987534 & -1263.981908 \\
\hline DeltaE, ha & 0.010157 & 0.008402 & 0.008332 & 0.008541 \\
\hline DeltaE, kJ/mol & 26.7 & 22.0 & 21.9 & 22.4 \\
\hline Chloro-curcumin-enol (H7) & -1723.594307 & - & -1723.610653 & - \\
\hline Chloro-curcumin-diketo-trans & -1723.585394 & - & -1723.606072 & - \\
\hline$\Delta$ E, kJ/mol & 23.4 & - & 12.0 & - \\
\hline Methyl-curcumin-enol (H13) & -1303.296165 & - & -1303.314579 & - \\
\hline Methyl-curcumin-diketo-trans & -1303.291764 & - & -1303.311699 & - \\
\hline$\Delta$ E, kJ/mol & 11.5 & - & 7.6 & - \\
\hline Butyl-curcumin-enol & -1421.392430 & - & -1421.289832 & - \\
\hline Butyl-curcumin-diketo-trans & -1421.401257 & - & -1421.282518 & - \\
\hline DeltaE, kJ/mol & 23.2 & - & 19.2 & - \\
\hline
\end{tabular}

\subsection{Barrier to interconversion}

The barrier to interconversion between the enol and the diketo-form is rather high, as both forms could be observed in the 13C NMR spectrum at low magnetic field (80 MHz NMR instrument) [33]. From a study of acetylacetone, the barrier was calculated as $62 \mathrm{Kcal}$, but with water present it reduced to $~ 30 \mathrm{Kcal}$ [34].

\subsection{Structural analysis}

Curcumin and its analogue can take up a number of conformations. Thus, it can be seen that the enol form can take up many different orientations with only a small energy difference. This should facilitate the binding to a receptor. For a structural view, including the energy differences we refer to the supplementary material (Fig. S1).

\subsection{Solubility}

Applying the ACD Percepta software [14], the predicted value (enol form) for the solubility in the gastrointestinal tract, Sol $_{\mathrm{GI}}$, to $0.11 \mathrm{mg} / \mathrm{ml}$. The Cp(Max) was found to be $0.29 \mu \mathrm{g} / \mathrm{mL}$, the oral bioavailability, $\mathrm{F}$, to $96,8 \%$ taking into account a first pass of $1.9 \%$ and the AUC (0 - INF) (oral): $4.57 \mu \mathrm{gxh} / \mathrm{ml}$ for Tmax $152 \mathrm{~min}$. Not surprisingly, due to the pH effect in the gastrointestinal tract, the corresponding values for the diketo form were found to be significantly lower. Thus, we find Sol $_{\mathrm{GI}}: 0.064 \mathrm{mg} / \mathrm{mL}, \mathrm{Cp}(\mathrm{Max}): 0.25 \mu \mathrm{g} / \mathrm{mL}, \mathrm{F}: 81.3 \%$ taking a first pass of $16 \%$ into account and an AUC (0 - INF) (oral): $3.95 \mu \mathrm{g} \times \mathrm{h} / \mathrm{ml}$ for Tmax $201 \mathrm{~min}$, respectively. 
As evident from the ADME figures for the enol and diketo form of curcumin given above in the introduction as well as the above discussion similar differences between enol and diketo form may prevail in the case of the here investigated substances (cf. Fig. 2 and Table 1). Furthermore, it may well be expected that from a drug point of view differences between enol and diketo form will be seen as being expressed by the probabilities for the studied effect for the two forms, respectively, i.e., the possible positive effect on prostate cancer treatment, and general anti-carcinogenic and anti-neoplastic effects, respectively.

Obviously, it is possible to rank the single compounds based on the single effects. In Fig. 5 the ranking of the 3 enol and diketo forms is visualized graphically based on the probability that the compounds possess prostate cancer treatment (PCT) ability, anti-neoplastic (AnNeo) and anti-carcinogenic (AnCar) activity, respectively.

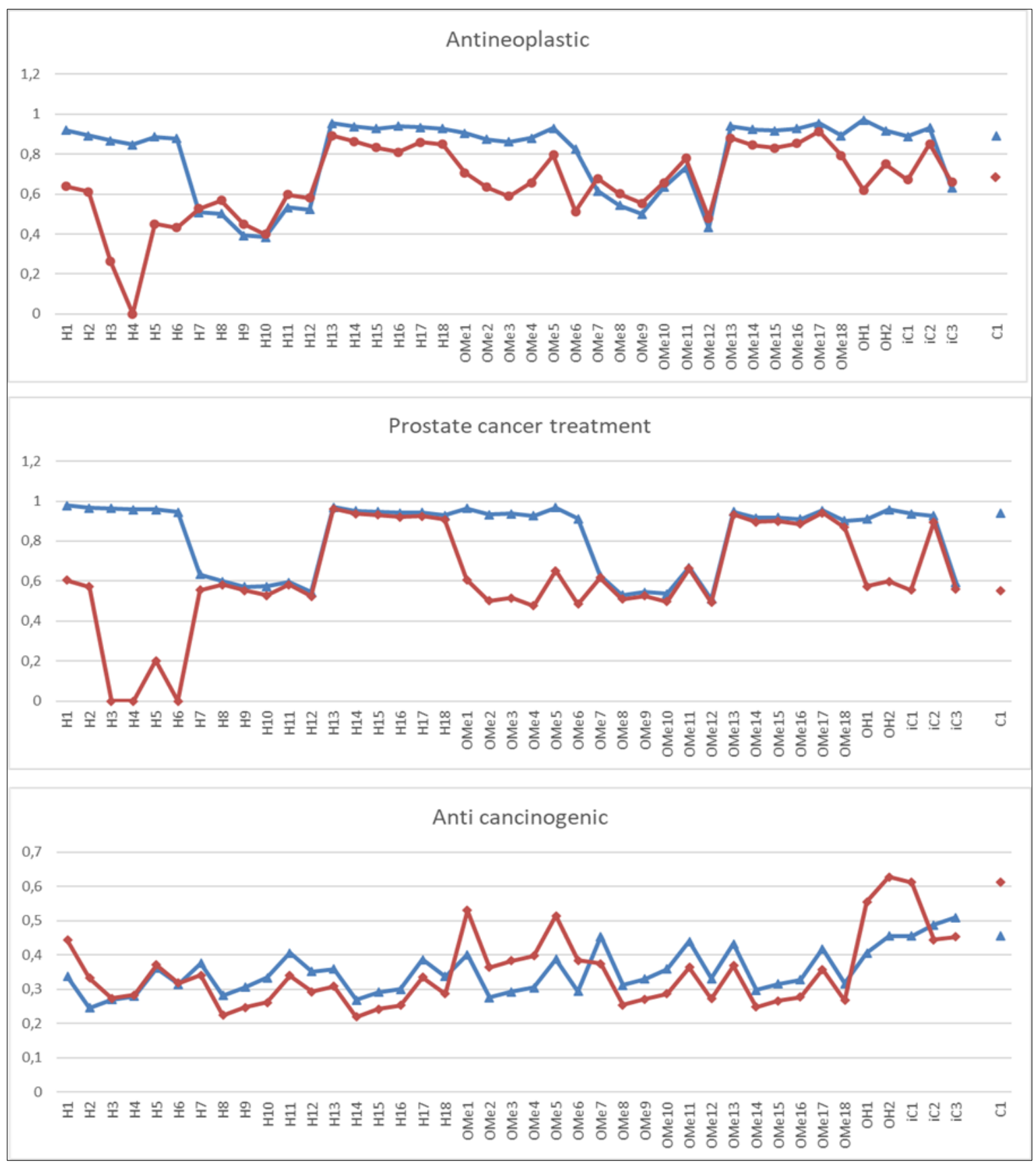


Figure 5 Ranking of the 23 enol (blue triangles) and 23 diketo (red diamonds) forms according to their calculated prostate cancer treatment (PCT) ability, anti-neoplastic (AnNeo) and anti-carcinogenic (AnCar) activity. For comparison, the values for the enol form (eC1) and the diketo form (kC1) of curcumin has been included

Immediately several interesting features become obvious. First, it is noted, that in the case of PCT and AnNeo the probabilities for the diketo forms in virtually all cases are lower or equal to those for the enol forms, whereas in the case of AnCar the probabilities for the two forms appear rather similar with no clear overall distinction between enol and diketo forms. For the PCT and AnNeo some distinct variations between the enol and diketo forms are noted. Thus, for the compounds $\mathrm{H} 1$ - H6 and OMe1 - OMe6, i.e., compounds with $\mathrm{R}_{2}=\mathrm{H}$ (Fig. 2/Table 1) the diketo forms display significantly lower probabilities that the enol forms and further for the compounds H7 - H12 and OMe7 - OMe12, i.e., R2 $=\mathrm{Cl}$, enol and diketo forms display pronounced lower, although almost identical probabilities. Also, in the cases of the $\mathrm{OH} 1, \mathrm{OH} 2$ and $\mathrm{iC} 1 \mathrm{a}$ preference for the enol form is noted, whereas for the anticarcinogenic effect the reverse trend can be noted.

Based on the above results (Fig. 5) it is obviously rather simple to select possible compounds for, e.g., prostate cancer treatment. Although many prostate cancers are benign, they can spread. A drug that can act more generally is therefore useful. So. if we want a drug that in addition to select a compound with a high probability for being a prostate cancer treatment drug also want to maximize the selection by looking at the probabilities for being active anti-neoplastic and anti-carcinogenic, we are facing a multi-indicator system (MIS). Thus, we have a MIS consisting of 84 compounds and 3 indicators. Often such challenges are treated by combining the indicators through some arithmetic procedure, possibly including weight for the single indicators. However, such an aggregation process is obviously subject to compensation effect [35], which may lead to less transparent results. To overcome this, we apply partial ordering to analyze the MIS $[22,23]$. In Fig. 6 the resulting Hasse diagram is shown displaying the best combination in the top of the diagram.

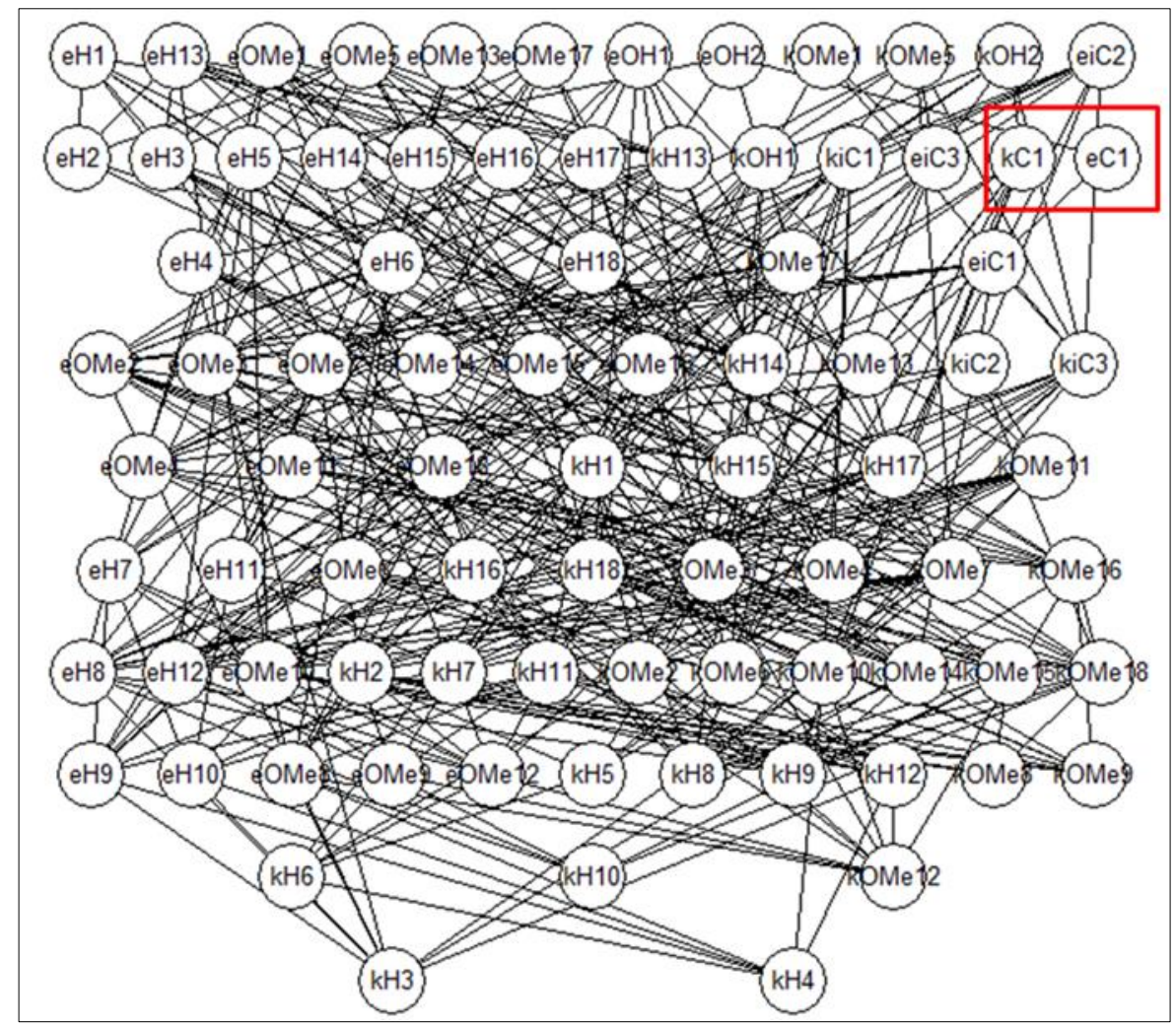

Figure 6 Hasse diagram based on probabilities for the 41 enols and 41 keto forms to be a prostate cancer treatment drug as well as the probabilities for being active anti-neoplastic and anti-carcinogenic. For comparison the enol form (eC1) and the diketo form (kC1) of curcumin has been included (red box)

The diagram is somewhat crowded, and it may be difficult to get a view of all details. To circumvent this, the average ranks of the single compounds are helpful. In Table 3 the average ranks for the 12 top ranked compounds is given. 
It is noticed that the 12 compounds in the top level actually are found among the 13 highest ranks. At rank 8, the enol form of the original curcumin (eC1) is found. It should be noted that it is not necessarily a general trend that, e.g., the top level consists of the compounds with highest ranks [29]. It is further noteworthy that among the here mentioned compounds, the enol forms are dominating. Thus, the top 9 compounds, incl. the eC1, are all enols.

With reference to Fig. 5 it is not surprising that the enol forms are dominating here. However, it may seem to be in contradiction with the above discussed variation in PCT and AnNeo, where we here find eOMe5, eOMe1, kOMe5, eH1, kOMe1 and eOMe11, which all appeared to have a decreased probability for these two indicators. However, looking at the relative importance of the three indicators the answer is clear. The relative importance of the three indicators is 0.101, 1.192 and 0.707 for AnNeo, PCT and AnCar, respectively. Thus, the AnCar indicator apparently in this MIS is by far the indicator with the highest impact. Turning to the probability variation of AnCar (Fig. 5) it can be seen that for the compounds that at first sight appeared surprising to find in the top nine, relative high probabilities for AnCar are found for these compounds apparently bringing them to the top of the Hasse diagram.

Table 3 The top 12 highest ranked compounds

\begin{tabular}{|l|l|}
\hline eOH2 & 1 \\
\hline eOMe5 & 2 \\
\hline eOMe17 & 3 \\
\hline eOMe13 & 4 \\
\hline eH13 & 5 \\
\hline eiC2 & 6 \\
\hline eOMe1 & 7 \\
\hline eH1 & 9 \\
\hline kOH2 & 10 \\
\hline kOMe5 & 11 \\
\hline eOH1 & 12 \\
\hline kOMe1 & 13 \\
\hline
\end{tabular}

In addition to the calculation of the probabilities for having a given effect, here to be a prostate cancer treatment drug as well as being active as anti-neoplastic and anti-carcinogenic drugs, also the probabilities for the single compounds not exhibiting these effects, $\mathrm{Pi}$, has been calculated [13\}. Typically, the Pi values was found in the range from approx. 0.002 to 0.05 . A partial order analysis verified that none of above top nine compounds exhibit Pi values above 0.03 . Thus, the top compounds based on the Pa values, i.e. eOMe5, eOMe17 and eOMe13 are found at rank 65, 71 and 72, respective based on the Pi values, i.e., rather inferior combined probabilities for not exhibiting the studied effects.

Based on the above a selection of potential candidates can be made. To illustrate this, the top six compounds, i.e., eOH2, eOMe5, eOMe17, eOMe13, eH13 and eiC2 have been selected. In Table 3 the ADME data for the three compounds are summarized together with that of curcumin. It is noted that eOMe5 and eOMe17 are quite similar, whereas e0Me13 and eH13 differ significantly, by pronounced lower values for solubility, Cp(Max), AUC and oral bioavailability, F. For eOH2 $\mathrm{F}$ was found at an intermediary level. In the case of eOMe13 the $\mathrm{R}_{1}=\mathrm{H}$ in contrast to eOMe 5 and eOMe17 with $\mathrm{R}_{1}=0 \mathrm{OMe}$. On the other hand, the variation in $\mathrm{R}_{2}$, i.e., $\mathrm{H}$ for eOMe5 and OMe for eOMe13 and eOMe17 (Table 1) apparently does not play a role.

Table 4 ADME data for the top six compounds found by the partial order analysis plus curcumin. Initial dose $=50 \mathrm{mg}$

\begin{tabular}{|l|c|c|c|c|c|c|}
\hline Compound & $\begin{array}{c}\text { Sol } \mathbf{G I} \\
(\mathbf{m g} / \mathbf{m L})\end{array}$ & $\begin{array}{c}\text { First pass } \\
\mathbf{( \% )}\end{array}$ & $\begin{array}{c}\text { Tmax } \\
\text { (min) }\end{array}$ & $\begin{array}{c}\text { Cp(Max) } \\
\boldsymbol{\mu g} / \mathbf{m L}\end{array}$ & $\begin{array}{c}\text { AUC(0- } \\
\text { INF) at } \\
\text { Tmax }\end{array}$ & $\begin{array}{c}\text { F (oral) } \\
\text { \% at } \\
\text { Tmax }\end{array}$ \\
\hline $\mathrm{eOH} 2$ & 0.025 & 1.2 & 298 & 0.21 & 2.84 & 67.3 \\
\hline
\end{tabular}




\begin{tabular}{|l|c|c|c|c|c|c|}
\hline eOMe5 & 0.096 & 1.8 & 159 & 0.31 & 3.51 & 96.8 \\
\hline eOMe17 & 0.089 & 1.8 & 168 & 0.19 & 2.32 & 96.5 \\
\hline eOMe13 & 0.01 & 1.9 & 383 & 0.04 & 0.86 & 36.9 \\
\hline eH13 & 0.0053 & 1.6 & 405 & 0.02 & 0.33 & 22.8 \\
\hline eiC2 & 0.058 & 3.0 & 216 & 0.17 & 2.74 & 92.7 \\
\hline Curcumin & 0.11 & 1.9 & 152 & 0.29 & 4.57 & 96.8 \\
\hline
\end{tabular}

In addition to the ADME data (Table 4) it is worthwhile to have a look at the druglikeness of the three compounds. Druglikeness has been suggested by several researchers like Lipinsky, Ghose, Veber, Egan and Muegge [15]. In Table 4 the druglikeness for the three compounds are summarized. It can be seen that none of the compounds actually fulfill all five criteria. It is noted that the violation for eOMe13 according to Muegge, i.e., a XLOGP value too high is consistent with the rather low solubility of the compound. This substantiate further that eOMe13 apparently is not the optimal choice.

On the other hand, the reported data, i.e., the partial ordering in combination with the ADME (Table 3) and druglikeness estimations (Table 5) suggest eOMe5 as the preferable candidate for further experimental studies.

Table 5 Druglikeness [15] (Swiss ADME, 2019) for the top six compounds and curcumin found by the partial order analysis. For comparison, the enol and diketo form of curcumin has been included (eC1 and kC1, respectively)

\begin{tabular}{|c|c|c|c|c|c|c|c|c|c|}
\hline Rule & eOH2 & e0Me5 ${ }^{1}$ & eOMe17² & e0Me13 3 & eH13 & $e^{e i C} 2^{3}$ & eC1 $^{4}$ & $\mathrm{kC1}^{5}$ & remarks \\
\hline Lipinsky & Yes & Yes & Yes & Yes & Yes & Yes & Yes & Yes & \\
\hline Ghose & Yes & Yes & No & Yes & Yes & Yes & Yes & Yes & $\begin{array}{l}{ }^{2} \text { Molecular } \\
\text { refractivity }>130\end{array}$ \\
\hline Veber & Yes & No & No & Yes & Yes & Yes & Yes & Yes & 1,2 Rotors $>10$ \\
\hline Egan & Yes & Yes & Yes & Yes & Yes & Yes & Yes & Yes & \\
\hline Muegge & Yes & yes & Yes & No & No & Yes & Yes & Yes & ${ }^{3}$ XLOGP > 5 \\
\hline
\end{tabular}

\section{Conclusion}

From the NMR and UV studies, the enol form is usually dominant in non-polar solvent. Substitution at C-2 with a large substituent increases the amount of the diketo-form. In addition, a polar solvent like water will increase the amount of the diketo-fom. As the barrier between the enol and the keto-form is rather high, these two forms will only equilibrate very slowly. In relation to effect vs. the three forms (prostate cancer, anti-neoplastic and anti-carcinogenic) the enol form is in most cases show the highest probabilities for being effective. However, in some cases like OMe5 both the enol and the diketo forms have rather similar ranking which means, that the fact that the diketo-form increases in water apparently does not decrease it probability for being effective. In more general term it is suggested that the actual enolketo ratio will not cause any significant variation on the possible therapeutic effects of the compounds here studied. However, some compounds will be favored as both forms show activity. It may seem somewhat surprising that the position of $\mathrm{OH}$ and $\mathrm{OCH}_{3}$ groups does not seem to have any significant effect on the probability. Thus, it looks like the more the better.

\section{Compliance with ethical standards}

\section{Disclosure of conflict of interest}

No conflict of interest. 


\section{References}

[1] Mbese X, Khwaza V, Aderibigbe BA. Curcumin and Its Derivatives as Potential Therapeutic Agents in Prostate, Colon and Breast Cancers. Molecules. 2019; 24: 4386.

[2] Giordano A, Tommonaro G. Curcumin and Cancer Nutrients. 2019; 11: 2376.

[3] Fuchs JR, Pandit B, Bhasin D, Etter JP, Regan N, Abdehamid DKi, Ch, Lin J, Li P-K. Structure-activity relationship studies of curcumin analogues. Biorg. Medical Chem. Letters. 2009; 19: 2065-2069.

[4] Lopresti AL. The Problem of Curcumin and Its Bioavailability: Could Its Gastrointestinal Influence Contribute to Its Overall Health-Enhancing Effects? Adv. Nutr. 2018; 9: 41-45.

[5] Liu D, Schwimer J, Liu Z, Woltering EA, Greenway FL. Antiangiogenic Effect of Curcumin in Pure Versus in Extract Forms. Pharm. Biol. 2008; 46: 677-682.

[6] Anand P, Kunnumakkar AB, Newman RA, Aggarwal BB. Bioavailability of Curcumin: Problems and Promises. Mol.Pharm. 2007; 4: 807-818.

[7] Cheng AL, Hsu CH, Lin JK, Hsu MM, Ho YF, Shen TS, Ko J, Lin JT, Lin BR, Ming-Shiang W, Yu HS, Jee SH, Chen GS, Chen TM, Chen CA, Lai MK, Pu YS, Pan MH, Wang YJ, Tsai CC, Hsieh CY. Phase I clinical trial of curcumin, a chemopreventive agent,in patients with high-risk or pre-malignant lesions. Anticancer Res. 2001; 21(4B): 2895900; PMID: 11712783.

[8] Shoba G, Joy D, Joseph T, Majeed M, Rajendran R, Srinivas PS. Influence of piperine on the pharmacokinetics of curcuminin animals and human volunteers. Planta Med. 1998; 64: 353-356.

[9] Lao CD, Ruffin MT, Normolle D, Heath DD, Murray SI, Bailey JM, Boggs ME, Crowell J, Rock CL, Brenner DE. Dose escalation of a curcuminoid formulation. BMC Complement Altern. Med. 2006; 6: 10.

[10] Sharma RA, Euden SA, Platton SL, Cooke DN, Shafayat A, Hewitt HR, Marczylo TH, Morgan B, Hemingway D, Plummer SM, Pirmohamed M, Gescher AJ, Steward WP. Phase I clinical trial of oral curcumin: biomarkers of systemic activity and compliance. Clin. Cancer Res. 2004; 10: 6847-54.

[11] Garcea G, Berry DP, Jones DJ, Singh R, Dennison AR, Farmer PB, Sharma RA, Steward WP, Gescher AJ. Consumption of the putative chemopreventive agent curcumin bycancer patients: assessment of curcumin levels in the colorectum and their pharmacodynamic consequences. Cancer Epidemiol. Biomarkers. Prev. 2005; 14: 120-5.

[12] OASIS, Department of Physical Chemistry, Laboratory of Mathematical Chemistry, "Prof. As. Zlatarov" University, Yakimov St. 1, 8010 Bourgas, Bulgaria. 2004.

[13] PASS Way2Drug, Institute of Biomedical Chemistry (IBMC). 2020. http://www.way2drug.com/

[14] ACD PhysChem, ADME \& Toxicity Calculations with Percepta Software, ACD/Labs. 2020. https://www.acdlabs.com/products/percepta/index.php

[15] Swiss ADME, Swiss Institute of Bioinformatics. 2019. http://swissadme.ch/index.php

[16] Becke AD. A new mixing of Hartree-Fock and local density-functional theories. J. Chem. Phys. 1993; 98: 13721377.

[17] Lee C, Yang W, Parr RG. Development of the Colle-Salvetti correlation-energy formula into a functional of the electron density. Phys. Rev. 1988; 37: 785-789.

[18] Gausian 2019, https://gaussian.com/gaussian16/ (accessed June 2021)

[19] Gonzalez L, Mo O, Yanez M. High-Level ab Initio Calculations on the Intramolecular Hydrogen Bond in Thiomalonaldehyde. J. Phys. Chem. A. 1977; 101: 9710-9719.

[20] Gonzalez L, Mo O, Yanez M. Density functional theory study on ethanol dimers and cyclicethanol trimers. J. Chem. Phys. 1999; 111: 3855-3861.

[21] Tomasi J, Mennucci B, Cammi R. Quantum mechanical continuum solvation models. Chem. Rev. 2005; 105: 2999-3094.

[22] Bruggemann R, Carlsen L. Introduction to partial order theory exemplified by the evaluation of sampling sites, in Partial Order in Environmental Sciences and Chemistry, eds.: Bruggemann, R., Carlsen, L., Springer, Berlin. 2006; 61-110. 
[23] Bruggemann R, Patil GP. Ranking and prioritization for multi-indicator systems - Introduction, Springer, New York. 2011.

[24] Bruggemann R, Münzer B. A Graph-Theoretical Tool for Priority Setting of Chemicals. Chemosphere. 1993; 27: 1729-1736.

[25] Bruggemann R, Voigt K. An Evaluation of Online Databases by Methods of Lattice Theory. Chemosphere. 1995; 31: 3585-3594.

[26] Bruggemann R, Voigt K. Basic Principles of Hasse Diagram Technique in Chemistry. Combinat.Chem. High Throughput Screen. 2008; 11: 756-769.

[27] Bubley R, Dyer M. Faster random generation of linear extensions. Discr.Math. 1999; 201: 81-88.

[28] Bruggemann R, Annoni P. Average heights in partially ordered sets. MATCH - Commun.Math.Comput.Chem. 2014; 71: $117-142$.

[29] Bruggemann R, Carlsen L. An Improved Estimation of Averaged Ranks of Partially Orders. MATCH Commun.Math.Comput.Chem. 2011; 65: 383-414.

[30] Bruggemann R, Carlsen L, Voigt K, Wieland R. PyHasse Software for Partial Order Analysis: Scientific Background and Description of Selected Module, in Multi-indicator Systems and Modelling in Partial Order, eds. by R. Bruggemann, R. Carlsen, L. Wittmann, J., Springer, New York. 2014.

[31] Pedersen U, Rasmussen PB, Lawesson SO. Synthesis of Naturally Occurring Curcuminoids and related compounds Liebigs. Ann. 1985: 1557-1569.

[32] Manolova Y, Deneva V, Antonov L, Drakalska E, Momekova D, Lambov N. The effect of the water on the curcumin tautomerism: A quantitative approach. Spectrochim. Acta Part A: Molecular and Biomolecular Spectroscopy. 2014; 132: 815-820.

[33] Payton F, Sandusky P, Alsworth WL. NMR Study of the solution structure of curcumin. Spectrochim. Acta A Mol. Biomol. Spectrosc. 2014; 132: 815-820.

[34] Alagona G, Ghio C. Keto-enol tautomerism in linear and cyclic $\beta$-diketones: A DFT study in vacuo and in solution. Int J Quantum Chem. 2008; 108: 1840-1855.

[35] Munda G. Social multi-criteria evaluation for a sustainable economy, Springer, Heidelberg, New York. 2008.
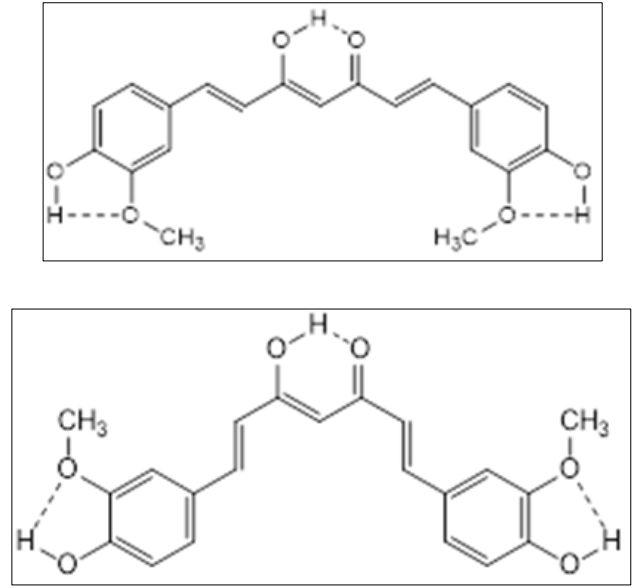

$3.67 \mathrm{Kcal}$

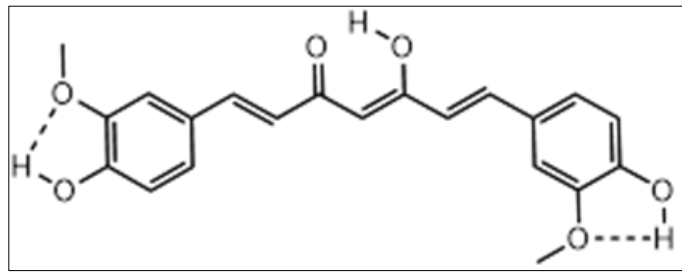

$0.02 \mathrm{Kcal}$

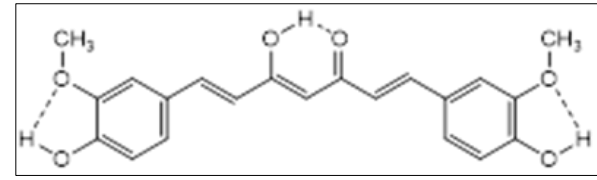

$0.12 \mathrm{Kcal}$

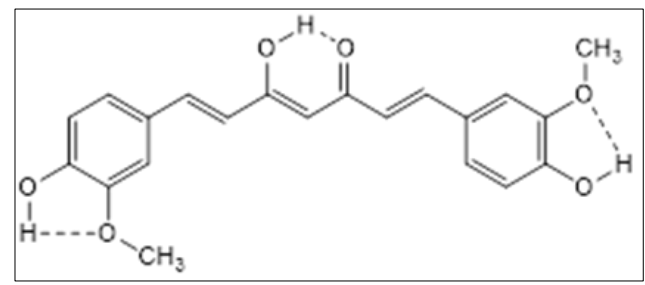

$-0.05 \mathrm{Kcal}$

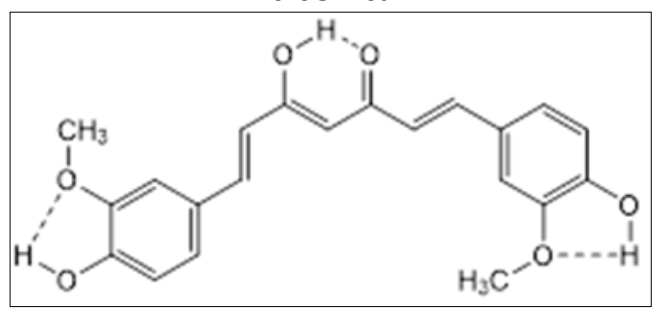

$2.20 \mathrm{Kcal}$ 


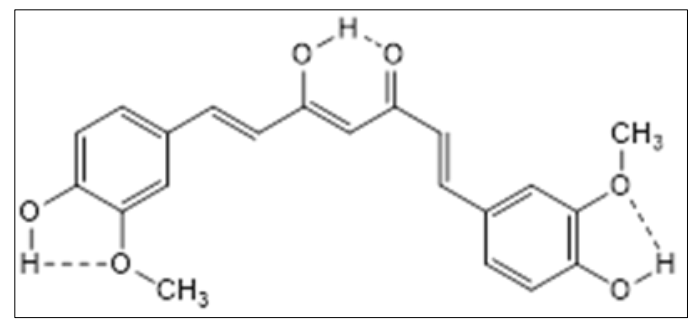

$1.33 \mathrm{Kcal}$

Figure S1 Conformations of the enol form of curcumin. Geometry optimization: B3LYP/6-311++(2d,p). Values relative to the top compound

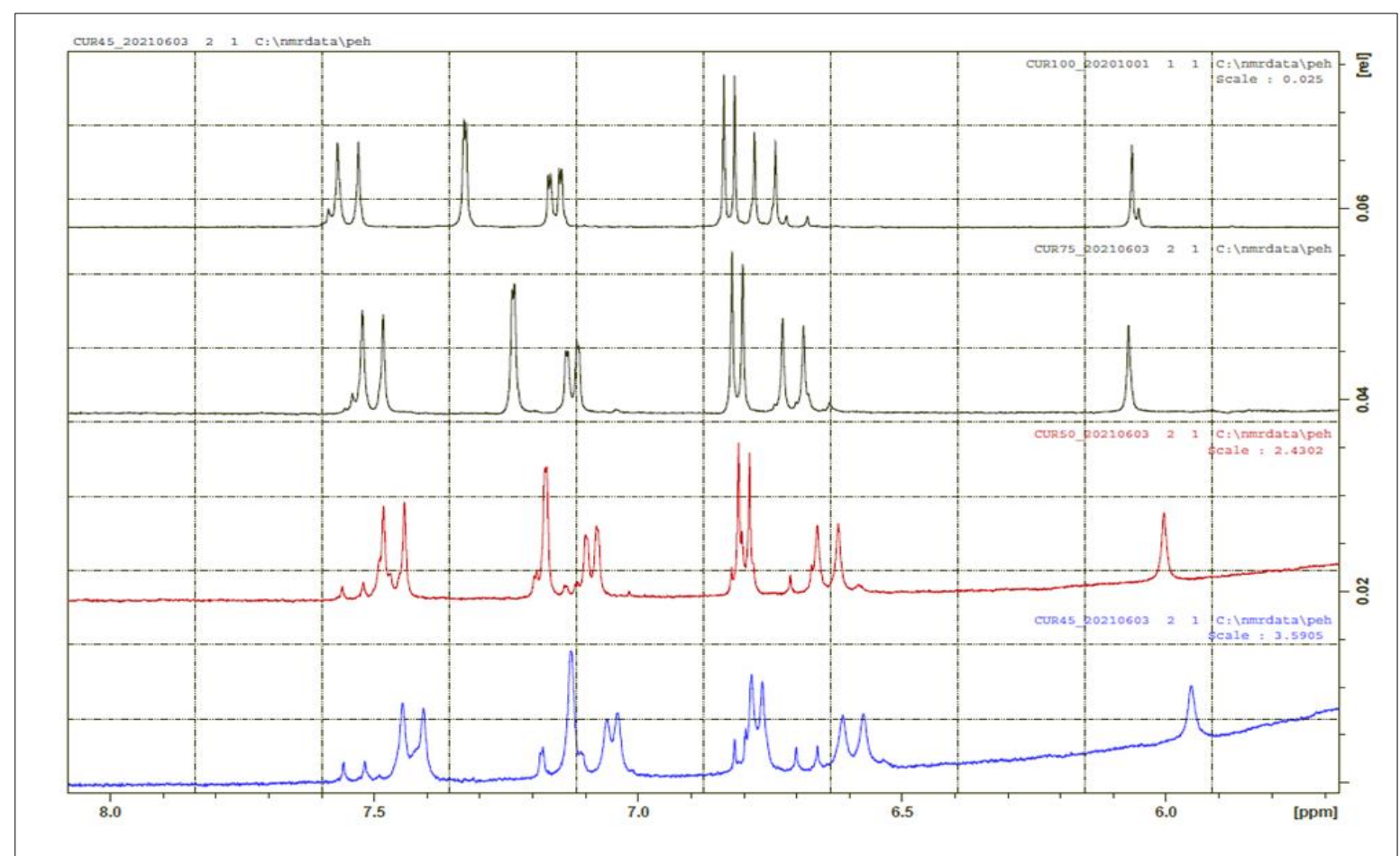


Figure S2 ${ }^{1} \mathrm{H}$ NMR spectra of curcumin. Top trace DMSO- $\mathrm{d}_{6}$, second $25 \%$ water, third $50 \%$ water, bottom $55 \%$ water. The smaller doublet are due to the keto-form

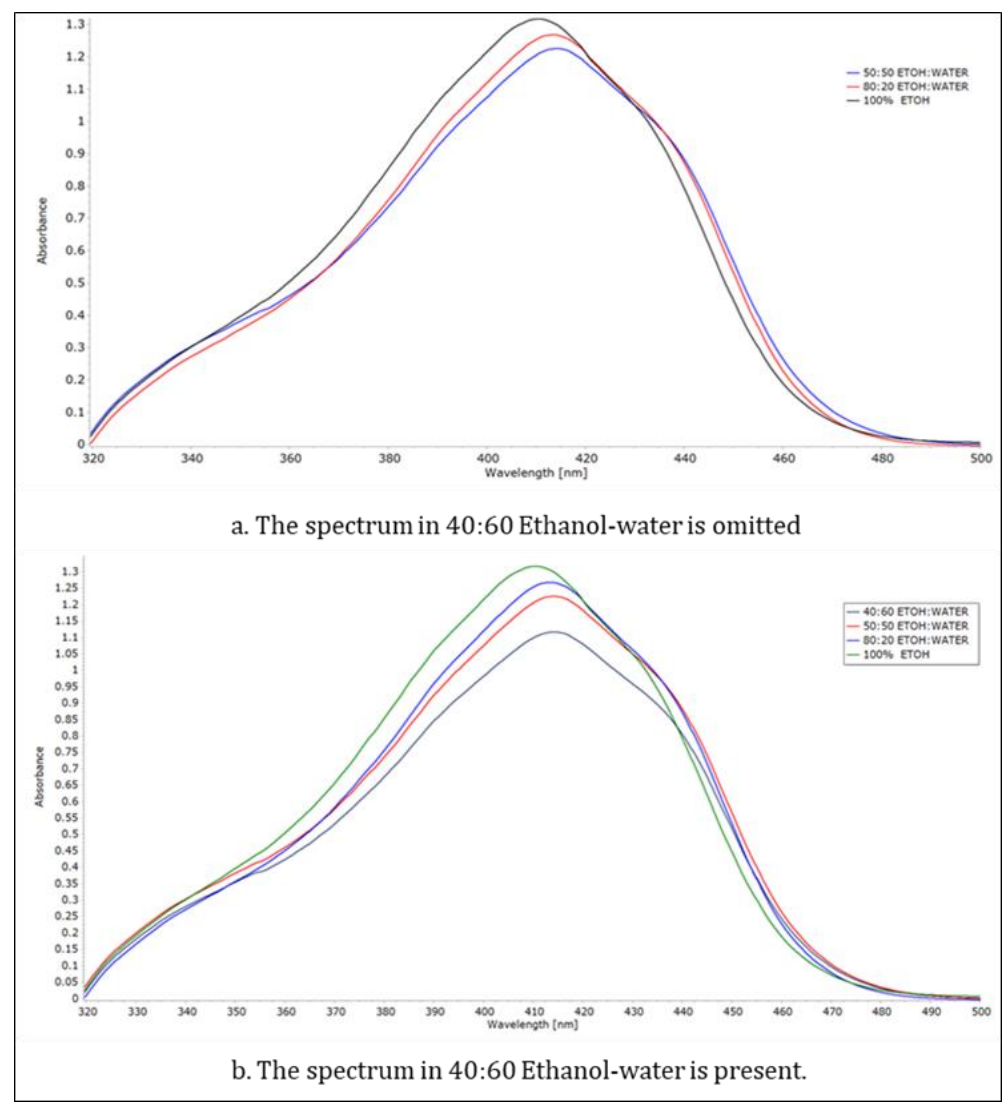

Figure 3S UV spectra of trimethoxycurcumin, $\mathrm{R}_{1}$ and $\mathrm{R}_{3}=\mathrm{CH}_{3}, \mathrm{R} 2=\mathrm{H}(\mathrm{OMe} 5)$. Solvent EtOH with water added

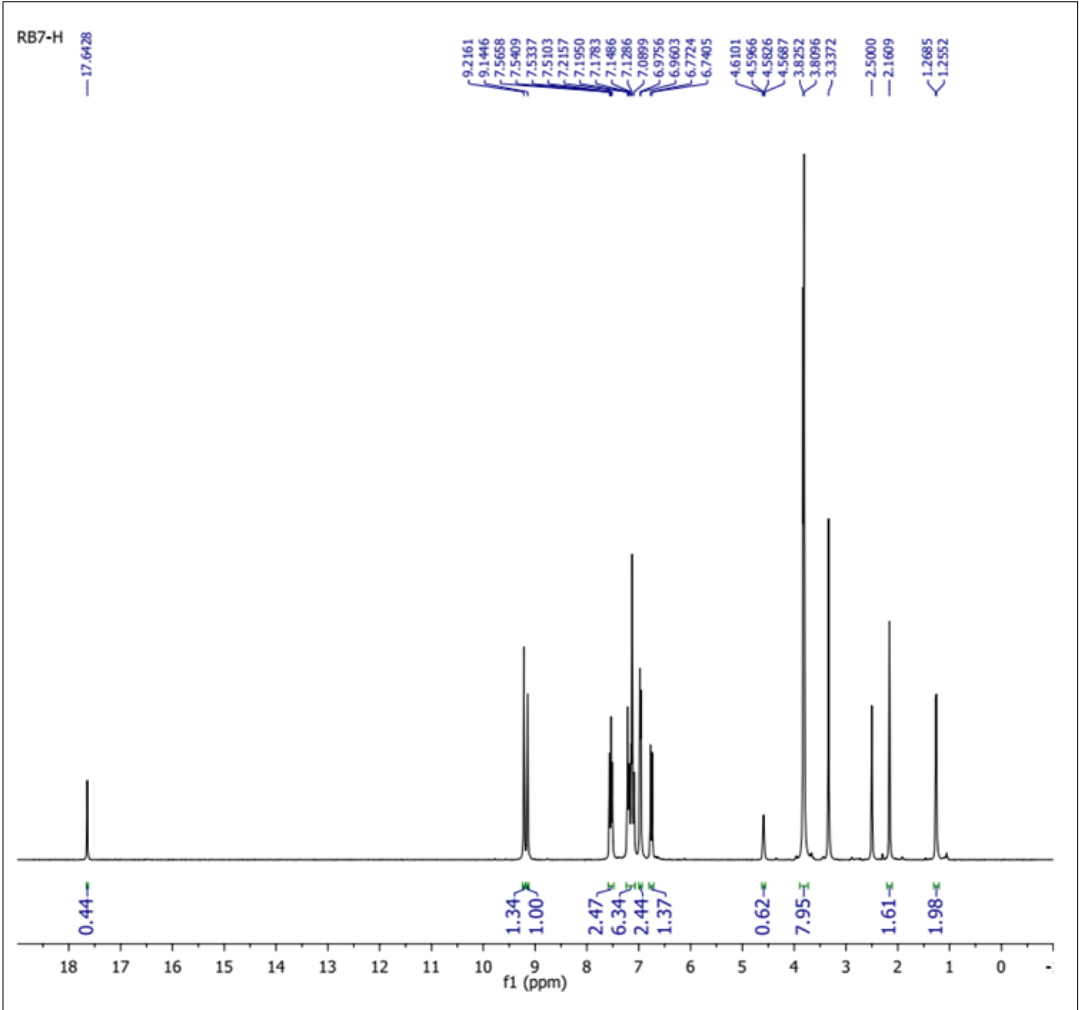


World Journal of Biological and Pharmaceutical Research, 2021, 01(02), 001-016

Figure $4 S^{1} \mathrm{H}$ NMR spectrum of $\alpha$-methylisocurcumin

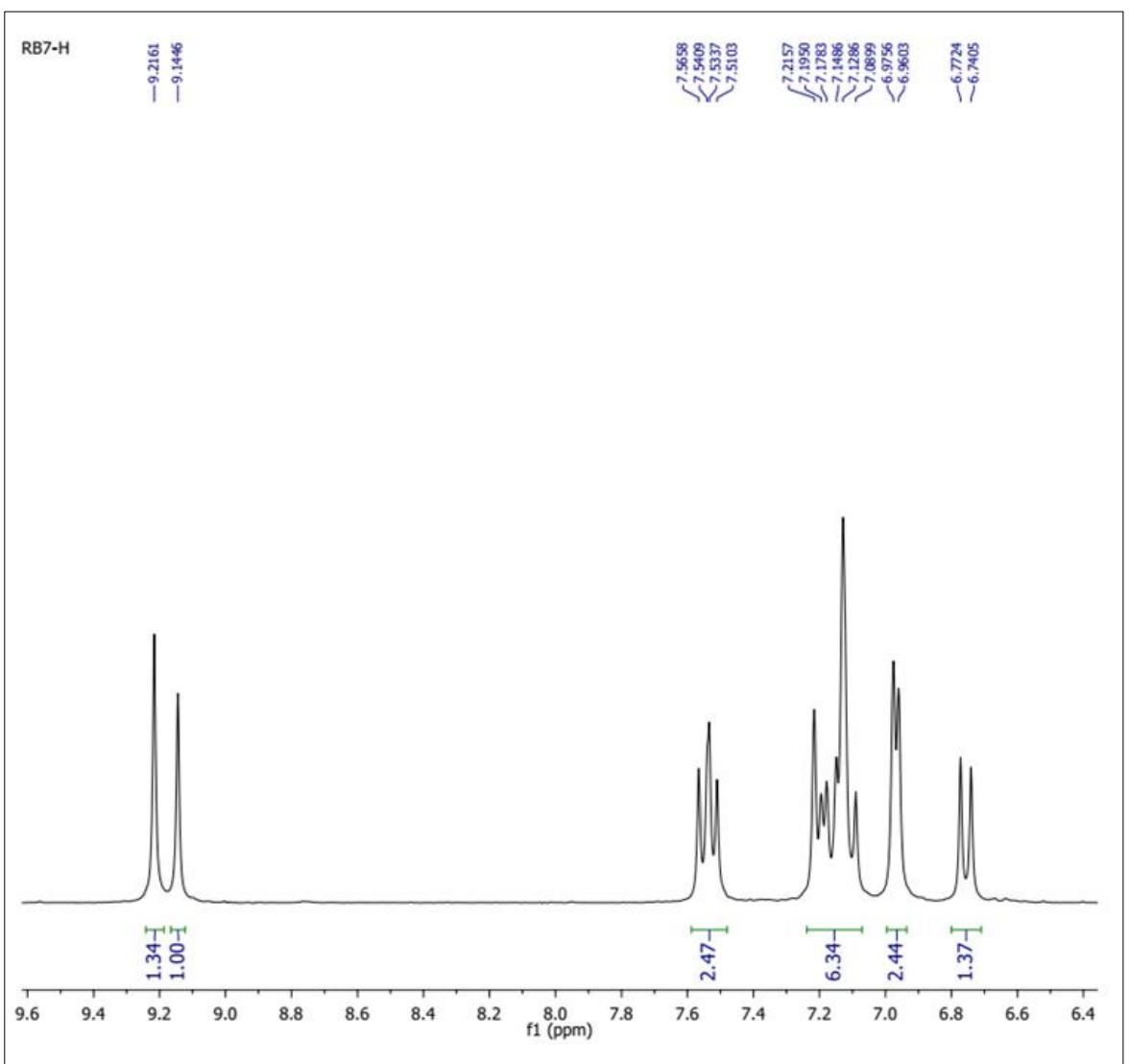

Figure 5S Expansion of 1H NMR spectrum of $\alpha$-methylisocurcumin 
World Journal of Biological and Pharmaceutical Research, 2021, 01(02), 001-016

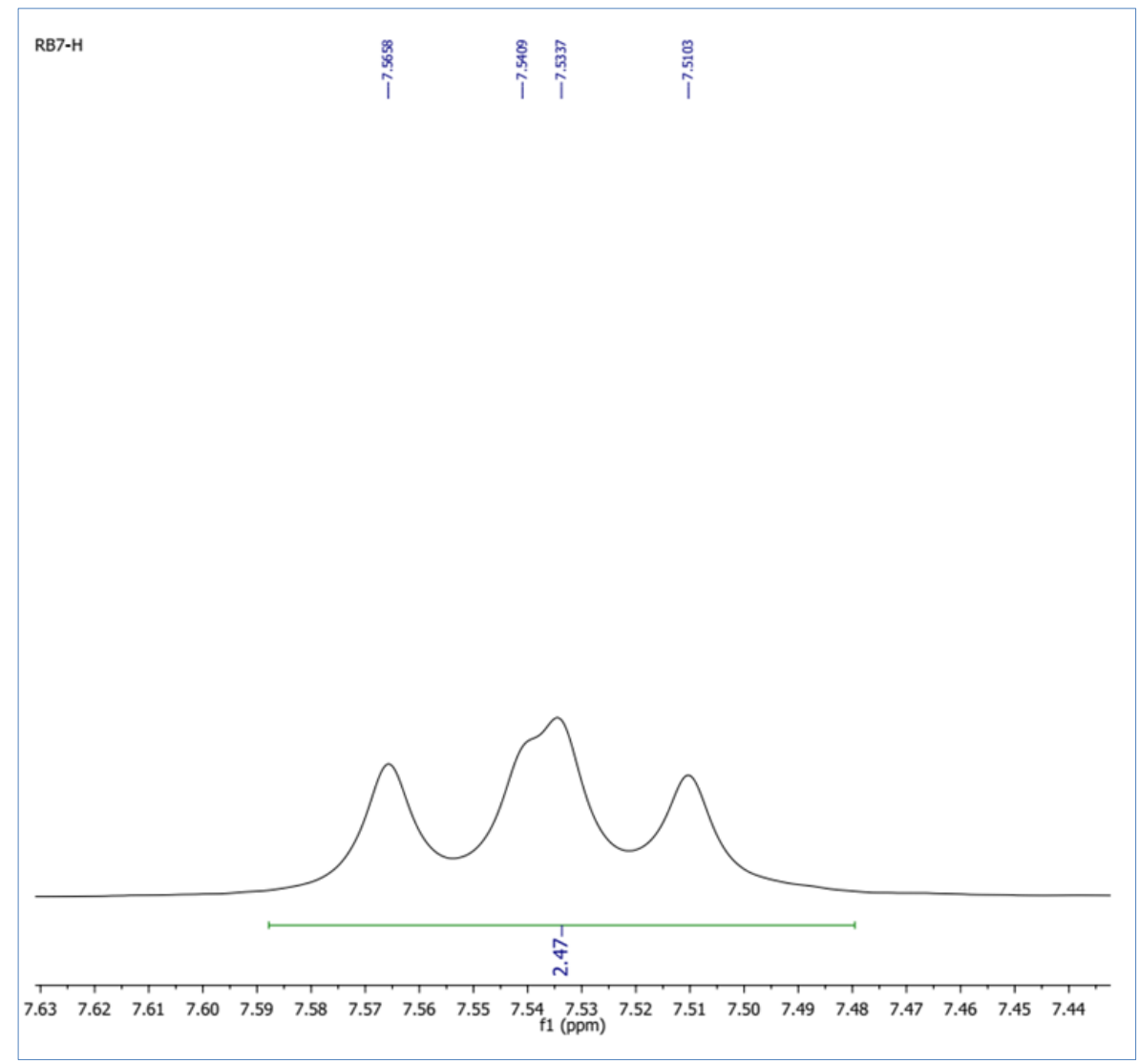

Figure 6S Expansion of 1H NMR spectrum of $\alpha$-methylisocurcumin

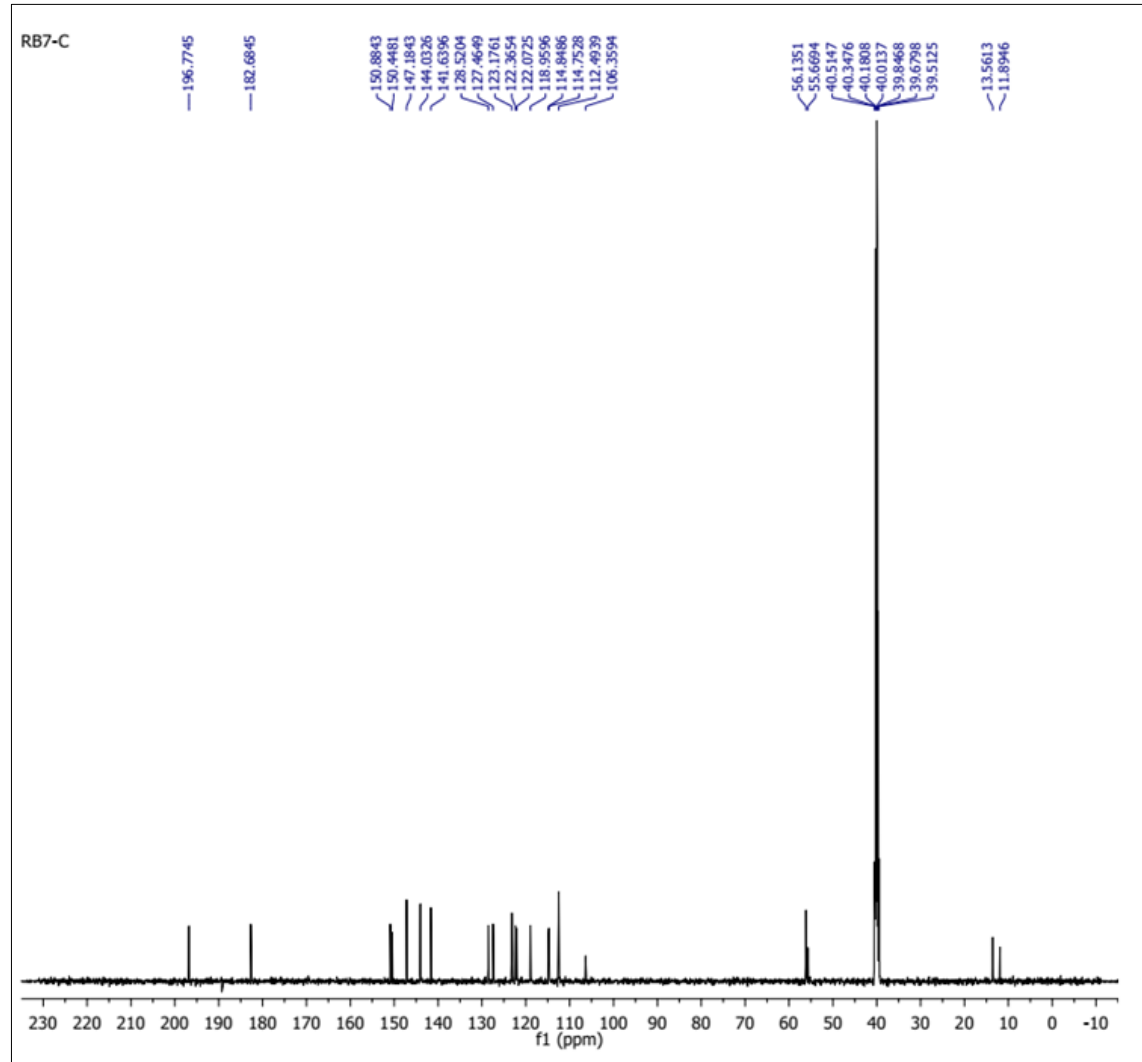

Figure 7S 13C NMR spectrum of $\alpha$-methylisocurcumin 
World Journal of Biological and Pharmaceutical Research, 2021, 01(02), 001-016

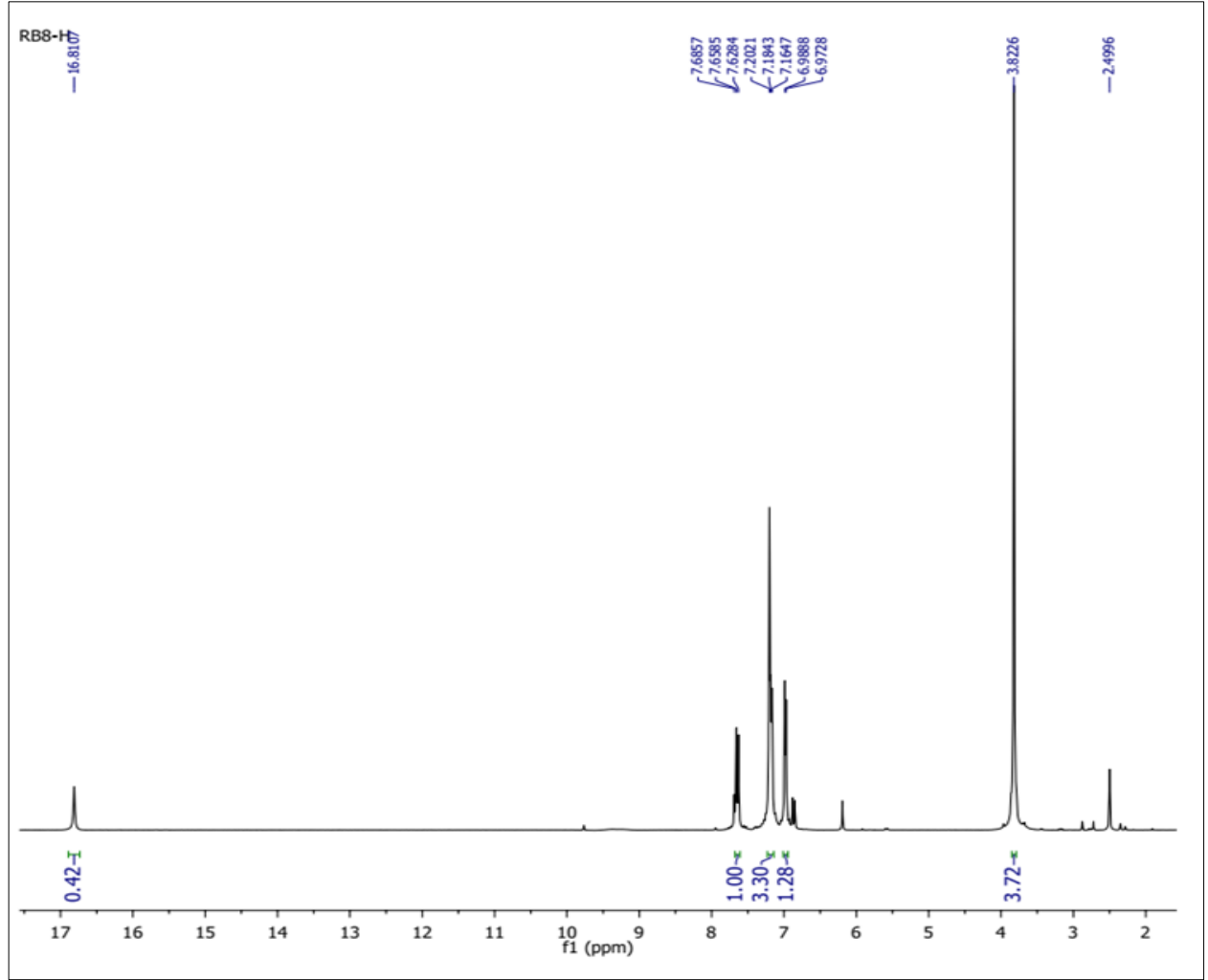

Figure 8S The $1 \mathrm{H}$ NMR spectrum if $\alpha$-chloroisocurcumin

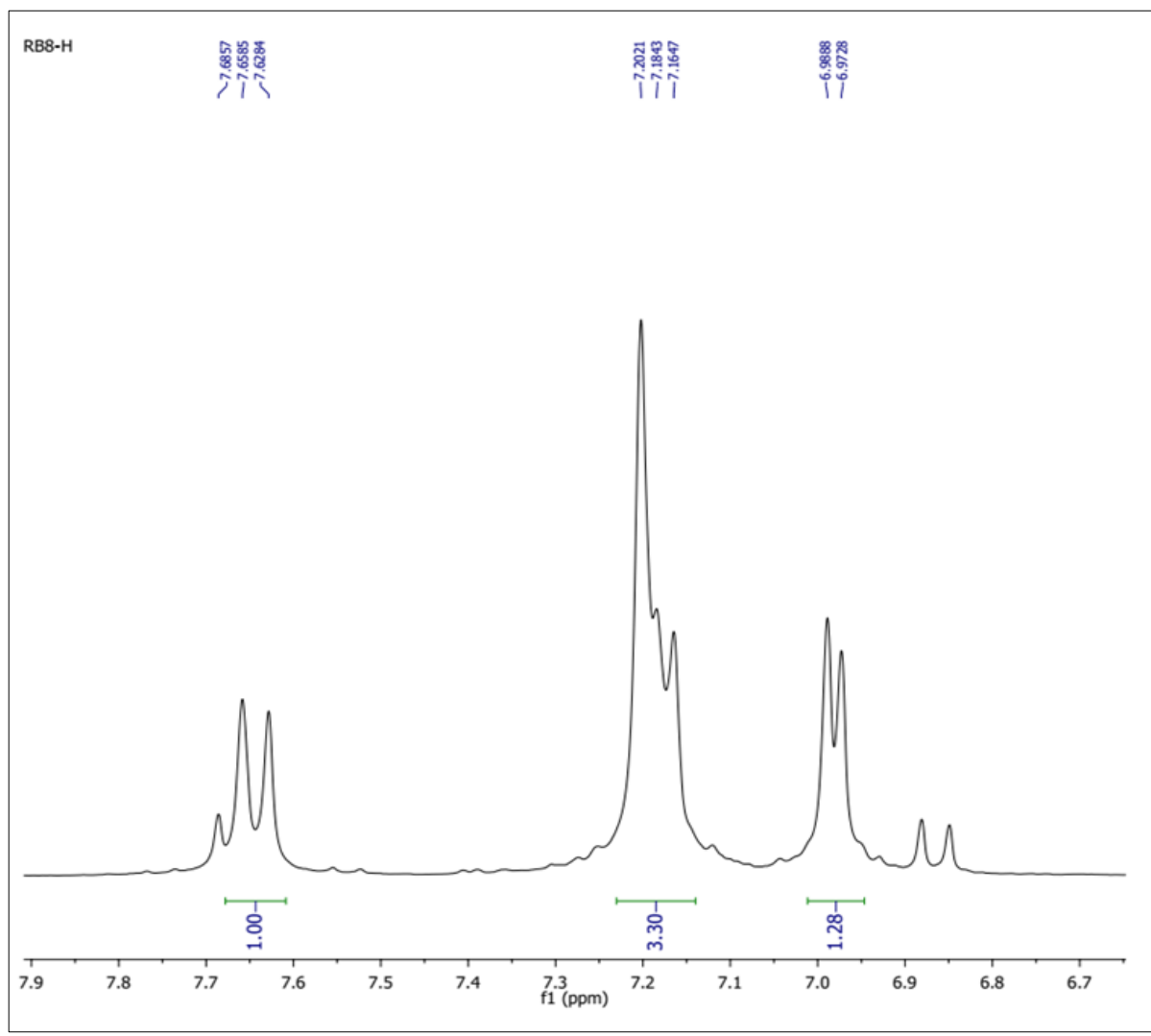

Figure 9S Expansion of 1H NMR spectrum of $\alpha$-chloroisocurcumin 


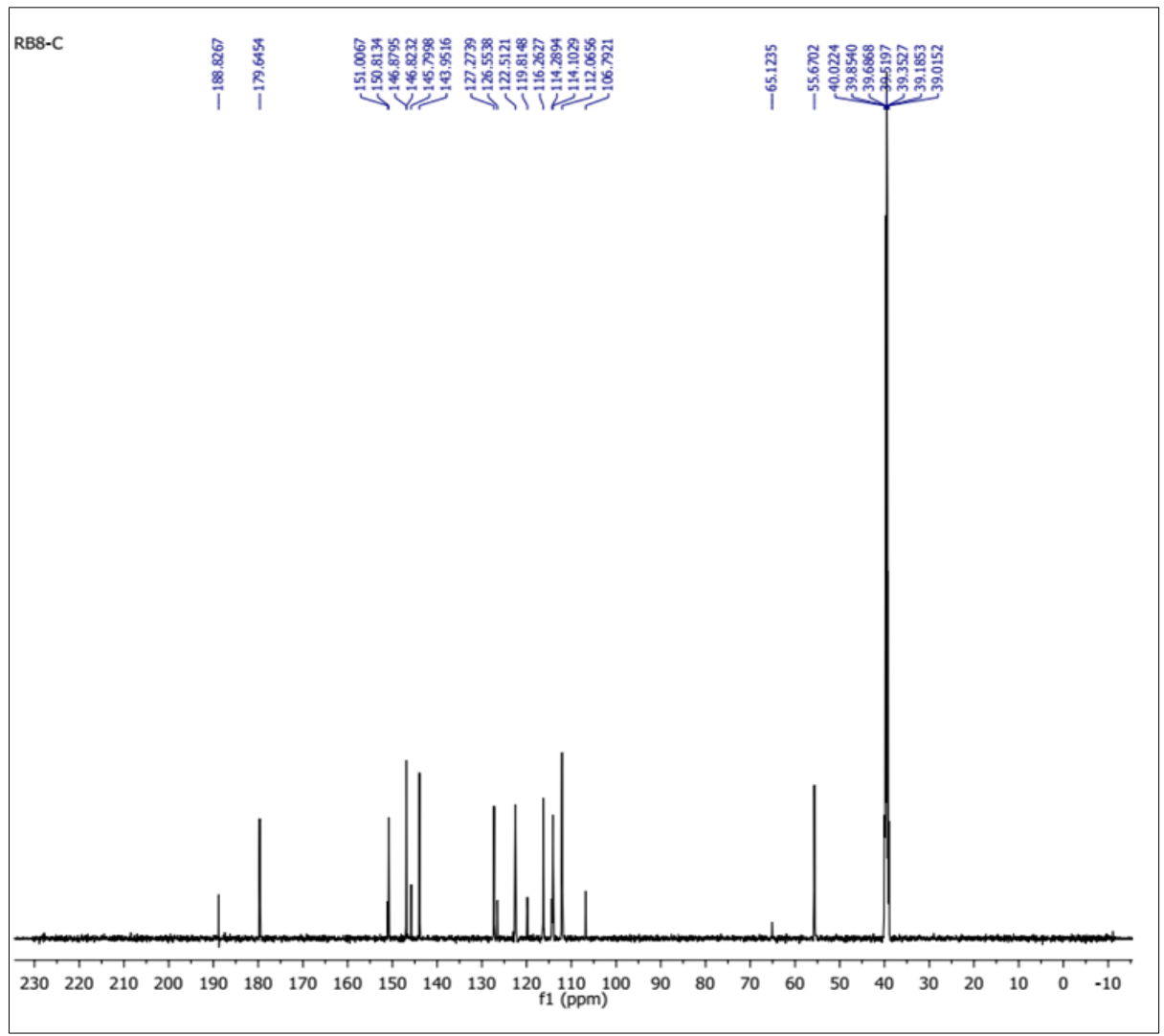

Figure $10 \mathrm{~S}$ The ${ }^{13} \mathrm{C}$ NMR spectrum of $\alpha$-chloroisocurcumin

Table S1 Spectroscopic characteristics of curcumin in different solvents

\begin{tabular}{|l|c|c|c|c|}
\hline phase & $\lambda \mathbf{m a x}(\mathbf{n m})$ & absorbance & $\boldsymbol{\lambda}$ (Shoulder) & absorbance \\
\hline 100\% ethanol & 411 & 1.317 & 355 & 0.443 \\
\hline 80:20 Ethanol-water & 413 & 1.268 & 355 & 0.398 \\
\hline 50:50 Ethanol-water & 413 & 1.22 & 355 & 0.42 \\
\hline 40:60 Ethanol-water & 413 & 1.12 & 355 & 0.39 \\
\hline
\end{tabular}

